\title{
Postoperative hypocalcemia: analysis of factors influencing early hypocalcemia development following thyroid surgery
}

\author{
Paolo Del Rio ${ }^{1 *}$, Matteo Rossini', Chiara Montana Montana', Lorenzo Viani', Giuseppe Pedrazzi², \\ Tommaso Loderer ${ }^{1}$ and Federico Cozzani ${ }^{1}$
}

\begin{abstract}
Background: Early Hypocalcemia is the most frequent complication after thyroid surgery. Several studies have tried to identify factors (patient caracteristics or surgical technique variations) affecting hypocalcemia following thyroid surgery. This studiy evaluates the role of several factors in postoperative hypocalcemia development.

Methods: A retrospective study conducted on 2108 patients that underwent thyroid surgery in a single center (1669 women and 439 men). Postoperative early hypocalcemia was defined as serum calcium levels lower than 8,0 $\mathrm{mg} / \mathrm{dl}$ measured $24 \mathrm{~h}$ after surgery. Following factors were evaluated in the study: sex, age, glandular hyperfunction, preoperative diagnosis, preoperative serum calcium levels, preoperative serum PTH levels, type of surgery performed (total thyroidectomy vs. lobectomy); minimally invasive video assisted thyroidectomy (MIVAT); number of parathyroid preserved in situ, postoperative serum calcium levels, changes in perioperative calcium levels (difference between preoperative values and postoperative calcium levels), presence of carcinoma in the surgical specimen, presence of thyroiditis based on histopatology reports.

Results: Among evaluated factors only gender and surgical procedure revealed to be significantly correlated to early hypocalcemia development. In fact female patients experienced postoperative hypocalcemia in 42\% (701/ 1669) of cases, which was signicantly higher than the $21.4 \%$ (94/439) identified in men. We also noticed a greater hypocalcemia incidence in patient undergoing total thyroidectomy (38.8\%) than in patient undergoing lobectomy group (13.8\%). Early hypocalcemia development didn't appear to be related to preoperative serum calcium levels but it showed a statistically significant correlation with perioperative serum calcium level drop.

Conclusion: This findings suggest that sex (female gender is a strong risk factor),surgical procedure and perioperative changes in serum calcium are the only factors (among all variables examined) that influence early hypocalcemia development.
\end{abstract}

Keywords: Hypocalcemia,Thyroidectomy,Thyroid disease,parathyroid

\section{Background}

Thyroyd surgery (total or near total thyroidectomy) can lead to serious complications, including transient or permanent cordal palsy or severe bleeding. However, hypocalcemia is the most frequent complication after thyroid surgery [1-3].

\footnotetext{
* Correspondence: paolo.delrio@unipr.it

${ }^{1}$ Department of Medicine and Surgery, General Surgery Unit, University

Hospital of Parma, Parma, Italy

Full list of author information is available at the end of the article
}

Transient hypocalcemia frequently complicates postoperative care of patients who have undergone thyroid surgery.

Post-thyroidectomy hypocalcemia arises because of parathyroid removal, devascularization and damage which induce a state of transient (or permanent) hypoparathyroidism.

Additional mechanisms, such as vitamin D deficiency, an acute increase in calcitonin serum levels (because of gland handling during surgery) or an "hungry bone syndrome" are believed to contribute to this process [4-8].

(c) The Author(s). 2019 Open Access This article is distributed under the terms of the Creative Commons Attribution 4.0 International License (http://creativecommons.org/licenses/by/4.0/), which permits unrestricted use, distribution, and reproduction in any medium, provided you give appropriate credit to the original author(s) and the source, provide a link to the Creative Commons license, and indicate if changes were made. The Creative Commons Public Domain Dedication waiver (http://creativecommons.org/publicdomain/zero/1.0/) applies to the data made available in this article, unless otherwise stated. 
Etiological considerations include post-operative alkalosis-induced hypocalcemia resulting from hyperventilation triggered by postoperative pain, and diluition hypocalcemia [9].

Even though the perfect knowledge of thyroidal anatomy regarding the embriological origin of parathyroid glands is the most concrete element to decrease incidence of post-operative hypocalcemia [10].

Although the rate of of hypocalcemia has decrease as parathyroid preserving techniques have developed, the rates of transient hypocalcemia still range between 6.9 and $49.0 \%$ of patient undergone thyroid surgery [11-16].

Surgeon's ability to predict the onset of postthyroidectomy hypocalcemia is very important for post-operative management. Early detection of any risk of developing hypocalcemia will reduce the hospital stay lenght and eliminate unnecessary laboratory examinations.

When hypocalcemia is predicted, treatment with profilactic calcium and vitamin D supplements can prevent the development of hypocalcemia symptoms and premature discharge of patients. Several studies tried to identify risk factors related to early hypocalcemia (EH) development after thyroid surgery, with different results.

Post-operative hypoparathyroidism remains a clinical challenge for thyroid surgeons because of its frequency and the limited number of established preoperative predictors [4].

In this study, factors related to the patient as well as surgical methods have been analyzed to find a significant correlations between them and EH development.

\section{Methods}

We have retrospectively analyzed the data of 2108 patients undergoing thyroid surgery at the Unit of General Surgery of the Parma University Hospital between January 2004 and June 2016. All surgeries were performed by the same surgical team experienced in endocrine surgery. All patients undergoing thyroid surgery were included regardless of the surgical indication for malignant or benign pathology.

We excluded patients undergoing thyroid surgery during the considered period whose postoperative calcium data were incomplete, patients with concomitant primary hyperparathyroidism, patients undergoing thyreoidectomy associated with neck dissection.

For each patient involved in the study, the following variables were analyzed.

Preoperative variables: Sex (further subdividing the female population in pre- and postmenopausal groups considering the age of 50 years as the limit between the two), Age (divided into 4 groups: age $<40,40<$ age $<50$, $50<$ age $<60$ and age $>60$ years), glandular hyperfunction, preoperative diagnosis (Benign pathology vs. malignant or suspected for malignancy disease), preoperative serum calcium levels, preoperative serum PTH levels (datas present for 813 patients), comorbidities (diabetes).

Surgical procedure characteristics: Type of surgery performed (total /near total thyroidectomy vs. lobectomy); traditional cervicotomic procedure vs. minimally invasive video assisted thyroidectomy (MIVAT); surgical approach to benign pathology vs approach for malignant pathology, number of parathyroid glands visualized by the surgeon during surgery (reported in 1202 cases).

Postoperative variables: Postoperative serum calcium levels ( $24 \mathrm{~h}$ after surgery), variations in perioperative calcium levels (difference between preoperative values and postoperative calcium levels), definitive histological examination report, presence of thyroiditis based on histopatology reports.

We have considered the presence of Early Hypocalcemia for calcium serum levels lower than $8.0 \mathrm{mg} / \mathrm{dl}$ measured $24 \mathrm{~h}$ after surgery.

Depending on the Early Hypocalcemia evidence, patients were divided into two groups and were compared considering the analyzed variables, attempting to highlight any statistically significant correlation between individual variables and the Early Hypocalcemia development.

Statistical data analysis was performed using SPSS (version 20.0; SPSS Inc. Chicago, IL, USA). To compare parametric variables, the Pearson chi-square test or Fisher's exact test was used. To compare non-parametric variables, Student $\mathrm{T}$ test or Mann-Whitney test $\mathrm{U}$ was used. Level of statistical significance was determined at $p<0.05$.

\section{Results}

We analyzed datas about a total number of 2108 patients that underwent thyroid surgery in the study period. There were1669 women (79.2\%) and 439 men (20.8\%) with a mean age of 54.65 years (range, 15-87). Patients' demographics, operative details, histological findings and postoperative events are reported in Table 1.

We divided all studied patients in age groups: 309 (14.7\%) patients younger than 40 years, 439 patients (20.8\%) aged between 40 and 50 years, 547 patients (26.0\%) aged between 50 and 60 years and 812 patients (38.5\%) older than 60 years.

Women in postmenopausal age were 1054 (63.2\%), the other 615 female patients (36.8\%) were younger than 50 years when the surgical procedure was performed.

Considering Preoperative diagnosis we divided patients in two groups: 1284 patients $(60.9 \%)$ underwent surgery for benign patology and 824 patients (39.1\%) underwent surgery for malignant patology or suspected for malignancy. Thyroid Hyperfunction was present in 382 patients (18.1\%). Thyroiditis was found in histopatological 
Table 1 Studied population characteristics

\begin{tabular}{|c|c|}
\hline Variable & Total n. Of patients (2108) \\
\hline \multicolumn{2}{|l|}{ Sex } \\
\hline Female & $1669(79.2 \%)$ \\
\hline Male & $439(20.8 \%)$ \\
\hline \multicolumn{2}{|l|}{ Age $(y)$} \\
\hline Mean $\pm s d$ & $54.6( \pm 13,85)$ \\
\hline Range & $15-87$ \\
\hline \multicolumn{2}{|l|}{ Age groups } \\
\hline$<40$ & $309(14.7 \%)$ \\
\hline $40-50[$ & $439(20.8 \%)$ \\
\hline $50-60[$ & $547(26 \%)$ \\
\hline$>60$ & $812(38.5 \%)$ \\
\hline \multicolumn{2}{|c|}{ Post-menopausal age (tot.1669) } \\
\hline Yes & $1054(63.2 \%)$ \\
\hline No & $615(36.8 \%)$ \\
\hline \multicolumn{2}{|c|}{ Preoperative diagnosis } \\
\hline Malignant & $824(39.1 \%)$ \\
\hline Benign & $1284(60.9 \%)$ \\
\hline \multicolumn{2}{|c|}{ Hyperthyroidism } \\
\hline Yes & $382(18.1 \%)$ \\
\hline No & $1726(81.9 \%)$ \\
\hline \multicolumn{2}{|l|}{ Thyroiditis } \\
\hline Yes & 727 (34.5\%) \\
\hline No & $1381(65.5 \%)$ \\
\hline \multicolumn{2}{|l|}{ Diabetes } \\
\hline Yes & $181(8.6 \%)$ \\
\hline No & $1927(91.4 \%)$ \\
\hline \multicolumn{2}{|l|}{ Hypertension } \\
\hline Yes & $601(28.5 \%)$ \\
\hline No & 1507 (71.5\%) \\
\hline
\end{tabular}

Definitive histological diagnosis (tot. 1914)

$\begin{array}{ll}\text { Malignant } & 667(34.8 \%) \\ \text { Benign } & 1247(65.2 \%) \\ \text { Surgical procedure } & \\ \text { Total thyroidectomy } & 2014(95.5 \%) \\ \text { Lobectomy } & 94(0.5 \%)\end{array}$

Total number of parathyroid glands identified during operation (tot. 1202)

$\begin{array}{lc}0 & 16(1.3 \%) \\ 1 & 68(5.7 \%) \\ 2 & 389(32.4 \%) \\ 3 & 656(54.6 \%) \\ 4 & 73(6.1 \%) \\ \text { Calcium drop from preoperative to postoperative }(24 \mathrm{~h}) \\ \text { Mean } \pm \text { sd } & 1.203( \pm 0.41) \mathrm{mg} / \mathrm{dl}\end{array}$

Table 1 Studied population characteristics (Continued)

\begin{tabular}{lc}
\hline Variable & Total $\mathrm{n}$. Of patients (2108) \\
\hline Postoperative early hypocalcemia $(\mathrm{ca}<8.0 \mathrm{mg} / \mathrm{dl})$ \\
Yes & $795(37.7 \%)$ \\
No & $1313(62.3 \%)$ \\
\hline
\end{tabular}

report of 727 patients (34.5\%) the other 1381 patients $(65.5 \%)$ didn't show signs of glandular cronic inflammation.

Based on final histopatological reports (datas were present in 1914 cases) we found the following results: 1247 patients were diagnosed of benign patology (65.2\%) while 667 patients have been found to be affected by malignant patology (34.8\%). By analyzing the surgical procedure performed we found out that total thyroidectomy was performed in 2014 cases (95.5\%) and lobectomy in 94 cases $(4.5 \%)$.

We considered also the number of identified parathyroid glands during surgery (datas were present in 1202 cases): 0 glands identified in 16 procedures (1.3\%), 1 gland identified in 68 procedures (5.7\%), 2 glands identified in 389 procedures (32.4\%), 3 glands identified in 656 cases $(54.6 \%)$ and 4 glands in 73 procedures $(6.1 \%)$.

Taking in consideration preoperative and postoperative serum calcium levels we found that there was a mean perioperative calcemia decrease of $1.203( \pm$ $0.41) \mathrm{mg} / \mathrm{dl}$.

Among patient comorbidities diabetes was present in 181 cases $(8.6 \%)$ and a medical history of arterial hypertension has been described in 601 cases (28.5\%).

Patients involved in the study were divided into two groups according to Early Hypocalcemia (EH) (postoperative serum calcium levels lower than $8 \mathrm{mg} / \mathrm{dL}$ ) detection.

Serum calcium levels lower than $8.0 \mathrm{mg} / \mathrm{dl} 24 \mathrm{~h}$ after surgery were observed in 795 patients out of the 2108 examined (37.7\%), thus forming the following 2 groups: Group N (normocalcemia) including 1313 out of 2108 patients (62.3\%) and Group EH (hypocalcemia) including 795 out of 2108 patients (37.7\%).

By analyzing patients mean age, the group of patients that developed EH shows a mean age of $55.03( \pm 13.87)$ years and in the $\mathrm{N}$ group the mean age is $54.01( \pm$ 13.47) years.

There was no statistically significant difference between the two groups.

Patients of both groups were then further subdivided into four age groups: patients under 40 years $(n=309)$ showed a development of Early Hypocalcemia in 36.9\% (114 out of 309) of cases. Patients aged 40 to 50 years ( $n=439$ ) developed $\mathrm{EH}$ in 43.3\% (190 out of 439) of cases; those patients aged between 50 and 60 years $(n=$ 547 ) developed $\mathrm{EH}$ in $38.6 \%$ (211 out of 547) cases and 
among the over 60 years old patients $(n=821)$ the incidence of $\mathrm{EH}$ was $34.5 \%$ (280 out of 812 ) cases.

There were no statistically significant differences between the different age groups, confirming the absence of correlation between patient age in the $\mathrm{EH}$ development process.

Analyzing male and female population within the study group there was a statistically significant difference $(p<0.0001)$ between men and women regard $\mathrm{EH}$ development.

Among men $(n=439)$ included in the database, $21.4 \%$ (94 out of 439) developed EH, while women $(N=1669)$ showed EH in $42 \%$ of cases (701 out of 1669). Female gender therefore appears to be a predisposing factor for the EH development.

The female population was subsequently divided on pre and post-menopausal age groups. The premenopausal women group (615 out of 1669) presented EH in $45.2 \%$ of cases, while the postmenopausal women group (1054 out of 1669)in $40.1 \%$ of cases. There was no statistically significant difference between the two groups.

Female sex therefore appears to favor EH development, but there is no statistically significant difference between pre and post-menopausal patients.

There are no statistically significant reports on the occurrence of $\mathrm{EH}$ considering preoperative diagnosis, we identified two gropus: benign pathology (Thyr 2, toxic pathology or multinodular goiter) and malignant pathology or suspect for malignancy (Thyr 3, Thyr 4, Thyr 5 and Thyr 6 following the Bethesda 2010 thyroid nodule classification based on citological examination by needle aspiration).

In the group including patients undergoing thyroid surgery for benign pathology (1284), EH was found in $38.5 \%$ of cases (494 out of 1284). Patients that underwent surgery for malignant thyroid disease (824) showed EH development in $36.5 \%$ (301 out of 824$)$ cases. $(P=$ 0.382).

Correlation between preoperative PTH serum levels (data present in 813 cases) and the onset of EH was observed. In the EH group the mean PTH value was 59.03 $( \pm 24.336) \mathrm{pg} / \mathrm{ml}$, in normocalcemic group mean PTH serum level was $56.78( \pm 21.195) \mathrm{pg} / \mathrm{ml}$. There was no statistically significant difference between the two groups $(p=0.367)$. Preoperative PTH serum level therefore appears to have no influence on the EH development.

Preoperative mean serum calcium level in patients in the EH group was $9.172( \pm 0.38) \mathrm{mg} / \mathrm{dL}$, not highlighting a statistically significant difference with $\mathrm{N}$ group patients where preoperative mean serum calcium level was $9,35( \pm 0.43) \mathrm{mg} / \mathrm{dl}$.

We noticed a statistically significant correlation between the variation of perioperative serum calcium level (difference between preoperative calcium and postoperative calcium) and EH development. In the EH group mean decrease in serum calcium value registered was $1.67( \pm 0.49) \mathrm{mg} / \mathrm{dl}$, in the $\mathrm{N}$ group the mean calcium level drop was $0.920( \pm 0.47) \mathrm{mg} / \mathrm{dl}$.

$\mathrm{EH}$ development does not therefore appear to be correlated with preoperative serum calcium level, but the breadth of the preoperative serum calcium decrease $(p<0.001)$ seems to play a crucial role.

Correlation between surgery performed (total thyroidectomy or monolateral lobectomy) and $\mathrm{EH}$ development was analyzed.

Patients undergoing total thyroidectomy $(n=2014)$ showed EH development in 38.8\% (782 of 2014) cases, showing a statistically significant difference $(\mathrm{p}<0.001)$ compared to the group including patients who underwent monolateral lobectomy (94 pts) which showed EH in $13.8 \%$ of cases (13 out of 94 ).

We also tried to analyze the correlation between $\mathrm{EH}$ development and thyroid hyperfunction (we considered patients undergoing surgery due to Graves's disease or multinodular toxic goitre) but no statistically significant differences showed up. Among hyperthyroid patients (382), 38.8\% ( $n=148)$ showed EH development, among euthyroid patients this percentage reached 37.5\% (647 out of 1726). Thyroid hyperfunction does not appear to affect the $\mathrm{EH}$ onset.

Correlation between final histopathological examination report (present in 1914 cases) and onset of $\mathrm{EH}$ was also observed.

Patients diagnosed with thyroid cancer with final histological examination $(n=667)$ showed EH in $40.5 \%$ (270 out of 667) cases; patients affected by benign pathology $(n=1247)$ developed EH in $36.7 \%$ (458 out of 1247) cases. Data analysis evidenced that there is no statistically significant correlation between the two groups $(p=0.114)$. In our study malignant thyroid disease does not therefore seem to affect the EH onset and surgery for malignant thyroid disease does not seem to be characterized by a higher incidence of $\mathrm{EH}$.

We compared the number of parathyroid glands identified during surgery (data present in 1202 cases) and the occurrence of $\mathrm{EH}$.

Evidence of EH was found in 38.4\% (28 out of 73) of cases when 4 parathyroid glands were described, in $33.7 \%$ (221 out of 656 ) of cases when 3 glands were described, in 32.1\% (125 Out of 389) of cases when 2 glands were identified by the surgeon and $20.6 \%$ (14 out of 68) of cases in wich a single parathyroid gland was shown intact. Among the 16 surgical reports that didn't describe parathyroid glands, EH was recorded in 2 single cases (12.5\%).

Thus a greater incidence of $\mathrm{EH}$ appeared when the number of parathyroid glands displayed during surgery increased, but this difference did not appear to be statistically significant $(p=0.63)$. 
We tried to identify a possible effect of thyroiditis (diagnosed during the histopatological examination) on the EH development. Patients affected by thyroiditis $(n=$ 727) showed EH development in $37.4 \%$ (272 out of 727) of cases, the other group, including patients not affected by thyroiditis showed EH development in 37.9\% (523 out of 1381) of cases.

There was no statistically significant difference between the two groups $(p=0.837)$.

Within the studied population, 181 patients were affected by Diabetes (type 1 and type 2); we analyzed correlation between diabetic disease and $\mathrm{EH}$ onset. Patients with diabetes developed $\mathrm{EH}$ in $34.8 \%$ of cases (63 out of 181 ), non-diabetic patients showed $\mathrm{EH}$ in $38 \%$ of cases (732 out of 1927). Thus, the presence of diabetes does not seem to affect EH appearance, there is no statistically significant difference between the two groups $(p=$ $0.399)$.

\section{Discussion}

Hypocalcemia is a common complication after thyroid surgery. It usually occurs in first days after surgery and it can be symptomatic or asymptomatic. The frequency of transient hypoparathyroidism after thyroid surgery is between 6.9 and $49 \%$ [11-16].

The mechanism of hypocalcemia after thyroidectomy is not precisely disclosed, although is accepted to be multifactorial; factors like surgical techique, parathyroid iatrogenic damage (injury, edema, infarction, ischemia), extent of thyroidectomy, hyperthyroidism, malignancy, patient gender, perioperative serum calcium drop, presence of thyroiditis, diabetes, number of identified parathyroid gland during surgery can be considered as etiological factors $[2,17,18]$.

Most studies underline the significance of expertise and surgeon's experience.

According to Literature, in the present study we noticed that $37.7 \%$ of patients that underwent tyroid surgery in our Unit developed early hypocalcemia $(E H)$, in fact we found serum calcium levels lower than $8.0 \mathrm{mg} / \mathrm{dl}$ $24 \mathrm{~h}$ after surgery in 795 patients on 2108. Because of this incidence we tried to find out patient caracteristics, disease related factors or surgical procedures that can influence the EH developmentt [11].

In literature, contrary opinions have been asserted about correlation between development of postoperative hypocalcemia and patient age. Some studies, found transient hypocalcemia to be associated with advanced age, whereas others reported an association with younger age. A systematic review performed by Edafe et al. Observed no significant difference in mean age between patients who had transient hypocalcemia and those who did not [18]. The present study also found no significant intergroup difference with regard to patient age. We also divided patients in four age groups (ved. Table 2) but no significant difference have been noticed between groups.

In most studies women were found to have significant higher rates of hypocalcemia $[11,13,18,19]$ whereas other studies showed that gender has no significant effect on the incidence of hypocalcemia [11, 19-22].

According to literature we identified sex as significant risk factor for hypocalcemia, in fact female seemed to be more prone to develop this complication. In fact in our study female patients experienced EH in 42\% (701/1669) of cases, which was significantly greater than the $21.4 \%$ (94/439) incidence detected in men $(p<0.001)$. There was no significant difference in rates of $\mathrm{EH}$ between premenopausal women and postmenopausal women, as confirmed by other studies [4].

Many studies tried to find an explanation to female predisposition to post-thyroidectomy hypocalcemia, but the specific mechanisms undelying this gender difference can only be assumed. The gender disparity may be related to effects of sex steroids on PTH secretion, genetic variation among cell-signaling pathways or anatomic differences that can cause more frequent iatrogenic damages because of a more diminutive operative field [4].

Some studies identified low preoperative level of serum calcium as a risk factor for the development of transient hypocalcemia [11, 19, 23-25]. In our study no difference has been identified between mean preoperative serum calcium level in EH group and in normocalcemic group. There was a significant difference in serum calcium level drop; mean perioperative variation in serum calcium levels (difference btween preoperative level and $24 \mathrm{~h}$ postoperative level) was significantly higher in patients that developed early hypocalcemia $(p<0.001)$. These findings clearly show that preoperative level of serum calcium has no influence on EH development, but perioperative level variation plays a decisive role in this process. This mechanism is confirmed by other studies in which a larger decrease in post-operative calcium from preoperativ levels was associated with transient hypocalcemia [19, 24, 26-28].

In literature hyperthyroidism is described as a risk factor for EH development; it is unclear why thyrotoxic thyroidectomies have an increased rate of hypocalcemia; however, it is perhaps unsurprising as the thyroid gland in thyrotoxicosis tends to be larger than normal and very highly vascularised leading to a more challenging operation $[1,29]$. In our study thyroid hyperfuntion didn't appear as a significant factor in EH development (Table 2 ) as confirmed by other studies in literature $[9,30]$.

Few articles in literature investigated effect diabetes has on hypocalcemia following thyroidectomy. Al-Dhahiri et al. Prospectively explored factors affecting recovery of parathyroid function after thyroidectomy and found diabetes mellitus to be a statistically 
Table 2 Studied population related to hypocalcemia

\begin{tabular}{|c|c|c|c|}
\hline Variable & $\begin{array}{l}\text { Hypocalcemia } \\
(n=795)\end{array}$ & $\begin{array}{l}\text { Normocalcemia } \\
(n=1313)\end{array}$ & $P$ value \\
\hline \multicolumn{4}{|l|}{ Sex } \\
\hline female & 701 (42\%) & 968 (58\%) & $P<0.0001$ \\
\hline male & $94(21.4 \%)$ & $345(78,6 \%)$ & \\
\hline \multicolumn{4}{|l|}{ Age (y) } \\
\hline $\begin{array}{l}\text { mean } \pm s d \\
\text { range }\end{array}$ & $55.03( \pm 13,87)$ & $54.01( \pm 13.47)$ & N.S. \\
\hline \multicolumn{4}{|l|}{ Age groups } \\
\hline$<40$ & $114(36.9 \%)$ & $195(63.1 \%)$ & \\
\hline $40-50[$ & $190(43.3 \%)$ & $249(56.7 \%)$ & \\
\hline $50-60[$ & $211(38.6 \%)$ & $336(61.4 \%)$ & N.S. \\
\hline$>60$ & $280(34.5 \%)$ & $532(65.5 \%)$ & \\
\hline \multicolumn{4}{|c|}{ Post-menopausal age (tot.1669) } \\
\hline yes & $40.1 \%$ & $59.9 \%$ & N.S. \\
\hline no & $45.2 \%$ & $54.8 \%$ & \\
\hline \multicolumn{4}{|l|}{ Preoperative diagnosis } \\
\hline malignant & $301(36.5 \%)$ & $523(63.5 \%)$ & N.S. \\
\hline benign & $494(38.5 \%)$ & $790(61.5 \%)$ & \\
\hline \multicolumn{4}{|l|}{ Hyperthyroidism } \\
\hline yes & $148(38.8 \%)$ & $234(61.2 \%)$ & N.S. \\
\hline no & 647 (37.5\%) & 1115 (62.5\%) & \\
\hline \multicolumn{4}{|l|}{ Thyroiditis } \\
\hline yes & $272(37.4 \%)$ & $455(62.6 \%)$ & N.S. \\
\hline no & $523(37.9 \%)$ & $858(62.1 \%)$ & \\
\hline \multicolumn{4}{|l|}{ Diabetes } \\
\hline yes & $63(34.8 \%)$ & $118(65.2 \%)$ & N.S. \\
\hline no & $732(38 \%)$ & $1195(62 \%)$ & \\
\hline \multicolumn{4}{|l|}{ Hypertension } \\
\hline yes & $181(31.3 \%)$ & $420(68.7 \%)$ & $P<0.001$ \\
\hline no & $607(40.3 \%)$ & $900(59.7 \%)$ & \\
\hline \multicolumn{4}{|c|}{ Definitive histological diagnosis (tot. 1914) } \\
\hline malignant & $270(40.5 \%)$ & $397(59.5 \%)$ & N.S. \\
\hline benign & $458(36.7 \%)$ & $789(63.7 \%)$ & \\
\hline \multicolumn{4}{|l|}{ Surgical procedure } \\
\hline total thyroidectomy & $782(38.8 \%)$ & $1232(61.2 \%)$ & $P<0.001$ \\
\hline lobectomy & $13(13.8 \%)$ & $81(86.2 \%)$ & \\
\hline
\end{tabular}

Total number of parathyroid glands identified during operation (tot. 1202)

\begin{tabular}{|c|c|c|}
\hline 0 & $2(12.5 \%)$ & \\
\hline 1 & $14(20.6 \%)$ & N.S. \\
\hline 2 & 125 (32.1\%) & \\
\hline 3 & $221(33.7 \%)$ & \\
\hline 4 & $28(38.4 \%)$ & \\
\hline
\end{tabular}

Preoperative calcium levels $(\mathrm{mg} / \mathrm{dl})$

$$
\text { mean } \pm s d \quad 9.172( \pm 0.38) \quad 9.35( \pm 0.43) \quad \text { N.S. }
$$

Table 2 Studied population related to hypocalcemia (Continued)

\begin{tabular}{lccl}
\hline Variable & $\begin{array}{l}\text { Hypocalcemia } \\
(n=795)\end{array}$ & $\begin{array}{l}\text { Normocalcemia } \\
(n=1313)\end{array}$ & $P$ value \\
\hline Preoperative pth $(\mathrm{pg} / \mathrm{ml})$ & & & \\
mean \pm sd (tot. 813) & $59.03( \pm 24.336)$ & $56.78( \pm 21.195)$ & N.S. \\
Calcium drop from preoperative to postoperative $(24 \mathrm{~h})$ & \\
mean \pm sd & $1.67( \pm 0.49)$ & $0.920( \pm 0.47)$ & $P<0.001$ \\
\hline
\end{tabular}

significant factor.[1, 30]The mechanism by which diabetes cause this effect is unclear; however, it is hypothesised that the small vessel disease and the impact on angiogenesis may leave the parathyroids more vulnerable to hypoxia in these patients. This hypotesis is not confirmed by our study,no significant difference $(p=0.399)$ was found between diabetic patients and patients not affected by diabetes regarding EH development.

The surgical technique and the extent of thyroidectomy are related to parathyroid injury, edema, infarction, ischemia or incidental parathyroidectomy [2, 11, 18]. Dissection carried around the parathyroid glands and efforts to isolate RLN in this region can lead to venous congestion and edema. In addition, ligating of thyroid veins is among the cause of venous stasis. Venous stasis and edema slow down parathyroid function and may cause a temporary hypoparathyroidism [17]. As confirmed by our study, the incidence of hypocalcemia is much lower among patients that underwent lobectomy $(13,8 \%)$ than in total thyroidectomy patient group (38.8\%).

Some authors described thyroidectomy for carcinoma as a higher risk operation because in case of malignant pathology posterior capsule is radically removed with the gland and this is the reason why parathyroid glands are at higher risk of injuryas the risk of nerve injury [17, 31-34]. In our study, as it has been described also in other studies [16], EH developed in $36.5 \%$ of patients with preoperative malignant or suspected malignant (Thyr 3, Thyr 4, Thyr 5) diagnosis, and in $38,5 \%$ of patients that underwent surgery for benign pathology. Surgery for malignant pathology was not found as a significant factor for the development of $\mathrm{EH}$.

The importance of systemic identification of all 4 parathyroid glands during thyroid surgery is one of the most controversial factors debated in the literature. Some authors recommend routinary physical identification and preservation of as many of parathyroid glands as possible [35]. Other series questioned this strategy [18, 3639]. Among our patients we noticed an increasing rate of $\mathrm{EH}$ when a higher number of parathyroid gland have been identified during surgery, but statistical analysis didn't show significant results $(p=0.63)$. To avoid potential injury to the parathyroid glands, every surgeon 
must be thoroughly aware of their anatomic complexity that contributes to difficulty of identification and possible injury. Strict adherence to capsular dissection represent the optimum method for safe preservation of parathyroid glands without necessitating their systemic identification. Distal ligation of all terminal branches of the superior and inferior thyroid arteries, close to the thyroid capsule, enables reliable separation of all tissues carrying parathyroid gland away from the thyroid surface. Continued dissection in this tissue, with the aim to identify all parathyroid glands may increase the risk of their mechanical injury or devascularization.

\section{Conclusion}

This findings suggest that sex (female gender is a strong risk factor), surgical procedure and perioperative changes in serum calcium are the only factors (among all variables examined) that influence early hypocalcemia development.

All the risk factors detected in our study appear to be very common and not editable before nor during or after surgical procedure. This is the reason why in our unit we are used to suggest prophylaxis against symptomatic hypocalcemia (Carbonate calcium $1 \mathrm{~g}$ and Vitamin D $0,50 \mathrm{mcg}$ per os twice a day for seven days) to every patient who underwent thyroid surgery. In our experience, therefore, prophylaxis with calcium and Vit. D (4 euros/ patient) during hospitalization and after patient discharge was found to be beneficial both in terms of clinical outcome and in terms of health costs. Since when we started this prophylaxis we noticed a decreased length of stay and minimization of re-entry.

\section{Abbreviations \\ EH: Early hypocalcemia; MIVAT: Miniinvasive Videoassisted thyroidectomy; $\mathrm{N}$ : Normocalcemia}

\section{Acknowledgments}

Not Applicable.

\section{Funding}

All Authors have no source of funding; This article did not receive sponsorship for publication.

\section{Availability of data and materials}

The datasets used and/or analysed during the current study are available from the corresponding author on reasonable request and from the $\mathrm{OU}$ of General Surgery of AOU of Parma.

\section{About this supplement}

This article has been published as part of BMC Surgery Volume 18 Supplement 1, 2018: Updates and New Technology in Endocrine Surgery. The full contents of the supplement are available online at https://bmcsurg.biomedcentral. com/articles/supplements/volume-18-supplement-1.

\section{Authors' contributions}

All authors contributed significantly to the present research and reviewed the entire manuscript. All the authors have read and approved the final manuscript. PDR: Participated substantially in conception, design and execution of the study and in the analysis and interpretation of the data; also participated substantially in the drafting and editing of the manuscript.
MR: Participated substantially in conception, design and execution of the study and in the analysis and interpretation of the data. CMM: Participated substantially in conception, design and execution of the study and in the analysis and interpretation of the data. PDR:paolo.delrio@unipr.it. LV: Participated substantially in conception, design and execution of the study and in the analysis and interpretation of the data. GP: Participated substantially in conception, design and execution of the study and in the analysis and interpretation of the data. TL: Participated substantially in conception, design and execution of the study and in the analysis and interpretation of the data. FC: Participated substantially in conception, design and execution of the study and in the analysis and interpretation of the data. CG: Participated substantially in conception, design and execution of the study and in the analysis and interpretation of the data.

Ethics approval and consent to participate

Ethical approval was given by AOU Parma Ethical Committee, Prot. N. 44,708 of 2017.

This is a retrospective study and no consent to participate to study was required.

Consent for publication

Not applicable.

Competing interests

The authors declare that they have no competing interests.

\section{Publisher's Note}

Springer Nature remains neutral with regard to jurisdictional claims in published maps and institutional affiliations.

\section{Author details}

${ }^{1}$ Department of Medicine and Surgery, General Surgery Unit, University Hospital of Parma, Parma, Italy. ${ }^{2}$ Department of Medicine and Surgery, University of Parma, Parma, Italy.

Received: 14 November 2018 Accepted: 30 January 2019 Published: 24 April 2019

\section{References}

1. Harris AS, Prades E, Tkachuk O, Zeitoun H. Better consenting for thyroidectomy: who has an increased risk of postoperative hypocalcemia? Eur Arch Otorhinolaryngol. 2016;273:4437-43.

2. Bhattacharyya N, Fried MP. Assessment of the morbidity and complications of total thyroidectomy. Arch Otolaryngol. 2002;128:389-92.

3. Sitges-Serra A, Ruiz S, Girvent M, Manjon H, Dueñas JP, Sancho JJ. Outcome of protracted hypoparathyroidism after total thyroidectomy. Br J Surg. 2010; 97:1687-95

4. Sands NB, Payne RJ, Côté V, Hier MP, Black MJ, Tamilia M. Female gender as a risk factor for transient post-thyroidectomy hypocalcemia. Otolaryngol Head Neck Surg. 2011;145(4):561-4.

5. Glinoer D, Andry G, Chantrain G, et al. Clinical aspects of early and late hypocalcemia after thyroid surgery. Eur J Surg Oncol. 2000;26:571-7.

6. McHenry C, Speroff T, Wentworth D, et al. Risk factors for postthyroidectomy hypocalcemia. Surgery. 1994;116:641-7.

7. Wingert D, Friesen S, lliopoulos J, et al. Post-thyroidectomy hypocalcemia: incidence and risk factors. Am J Surg. 1986;152:606-10.

8. Watson C, Steed D, Robinson A, et al. The role of calcitonin and parathyroid hormone in the patogenesis of post-thyroidectomy hypocalcemia. Metabolism. 1981:152:606-10.

9. Ozemir IA, Buldanli MZ, Yener O, et al. Factors affecting postoperative hypocalcemia after thyroid surgery: importance of incidental parathyroidectomy. North Clin Istambul. 2016;3(1):9-14.

10. Del Rio P, lapichino G, De Simone B, Bezer L, Arcuri MF, Sianesi M. Is it possible to identify a risk factor condition of hypocalcemia in patients candidates to thyroidectomy for benign disease? Annal Ital Chir 2010;81: 397-401.

11. Kakava K, Tournis S, Papadakis G, et al. Postsurgical hypoparathyroidism: a systematic review. In vivo. 2016;30:171-80.

12. Goncalves Filho J, Kowalski LP. Surgical complications after thyroid surgery performed in a cancer hospital. Otolaryngol Head Neck Surg. 2005;132:490-4 
13. Tomusch O, Machens A, Sekulla C, Ukkat J, Brauckhoff M, Dralle H. The impact of surgical technique on postoperative hypoparathyroidism in bilateral thyroid surgery; a multivariate analysis of 5846 consecutive patients. Surgery. 2003;133:180-5.

14. Cranshaw IM, Moss D, Whineray-Kelly E, Harman CR. Intraoperative parathormone measurement from the internala jugular vein predicts postthyroidectomy hypocalcemia. Langenbeck's Arch Surg. 2007;392:699-702.

15. Falk SA, Birken EA, Baran DT. Temporary post-thyroidectomy hypocalcemia. Arch Otolaryngol Head Neck Surg. 1988;114:168-74.

16. Calò PG, Conzo G, Raffaelli M, Medas F, Gambardella C, De Crea C, Gordini L, Patrone R, Sessa L, Erdas E, Tartaglia E, Lombardi CP. Total thyroidectomy alone versus ipsilateral versus bilateral prophylactic central neck dissection in clinically node-negative differentiated thyroid carcinoma.A retrospective multicenter study. Eur J Surg Oncol. 2017;43(1):126-32.

17. Kalyoncu D, Gonullu D, Gedik ML, et al. Analysis of the factors that have effect on hypocalcemia following thyroidectomy. Ulusal Cer Derg. 2013;29: 171-6.

18. Bergamaschi R, Becouarn G, Ronceray J, Arnaud JP. Morbidity and complication of total thyroidectomy. Am J Surg. 1998;176:71-5.

19. Edafe O, Antakia R, Laskar N, Uttley L, Balasubramanian SP. Systematic review and meta-analysis of predictors of post-thyroidectomy hypocalcemia. BJS. 2014;101:307-20.

20. Ozogul B, Akcay MN, Akcay G, Bulut OH. Factors affecting hypocalcemia following total thyroidectomy: aprospective study. Eurasian J Med. 2014;46: $15-21$.

21. Abboud B, Sargi Z, Akkam M, Sleilaty F. Risk factors for post-thyroidectomy hypocalcemia. World J Surg. 2002;195:456-61.

22. Filho JG, Kowalski LP. Postoperative complications of thyroidectomy for differentiated thyroid carcinoma. J Am Coll Surg. 2000;195:456-61.

23. Amir A, Sands NB, Tamilia M, Hier MP, Black MJ, Payne RJ. Preoperative serum calcium levels as an indicator of post-thyroidectomy hypocalcemia. J Otolaryngol Head Neck Surg. 2010;39:654-8.

24. Lang BH, Yih PC, Ng KK. A prospective evaluation of quick intraoperative parathyroid hormone assay at the time of skin closure in predicting clinically relevant hypocalcemia after thyroidectomy. World J Surg. 2012;36: 1300-6.

25. Ali S, Yu C, Palmer FL, Ganly Y, et al. Nomogram to aid selection of patients for short-stay thyroidectomy based on risk of postoperative hypocalcemia. Arch Otolaryngol Head Neck Surg. 2011;137:1154-60.

26. Walsh SR, Kumar B, Coveney EC. Serum calcium slope predicts hypocalcemia following thyroid surgery. Int J Surg. 2007;5:41-4.

27. Luu Q, Andersen PE, Adams J, Wax MK, Cohen J. The predictive value of perioperative calcium levels after thyroid/parathyroid surgery. Head Neck. 2002;24:63-7.

28. Yamashita H, Murakami T, Noguchi S, et al. Postoperative tetany in graves disease: important role of vitamin D metabolites. Ann Surg. 1999;229:23754.

29. Zambudio A, Rodriguez J, Riquelme J, Soria T, Canteras M, Parilla P. Prospective study of postoperative complications after total thyroidectomy for multinodular goiters by surgeon surgeons with experience in endocrine surgery. Ann Surg. 2004;240:18-25.

30. Noureldine SI, Genther DJ, Lopez M, Agrawal N, Tufano RP. Early predictors of hypocalcemia after total thyroidectomy: an analysis of 304 patients using a short-stay monitoring protocol. Otolaryngol Head Neck Surg. 2014;140: 1006-13.

31. Del Rio P, Arcuri MF, Cataldo S, De Simone B, Pisani P, Sianesi M. Are we changing our inclusion criteria for the minimally invaisve videoassisted thyroidectomy? Ann Ital Chir. 2014;85:28-32.

32. Michie W, Duncan T, Hamer-Hodges DW, et al. Mechanism of hypocalcemia after thyroidectomy for toxicosis. Lancet. 1971;1:508-14.

33. Testini M, Rosato $L$, Avenia $N$, et al. The impact of single parathyroid gland autotransplantation during thyroid surgery on postoperative hypoparathyroidism: amulticenter study. Transplant Proc. 2007;39:225-30.

34. Gambardella G, Polistena A, Sanguinetti A, Patrone R, Napolitano S, Esposito D, Testa D, Marotta V, Faggiano A, Calò PG, Avenia N, Conzo G. Unintentional recurrent laryngeal nerve injuries following thyroidectomy:is it the surgeon who pays the bill? Int J Surg. 2017;41:S55-9.

35. Sianesi M, Del Rio P, Arcuri MF, Cataldo S, Robuschi G. Post-thyroidectomy hypocalcemia. Ann Ital Chir. 2006;77:295-8.
36. Prazenica P, O'Keeffe L, Holy R. Dissection and identification of parathyroid glands during thyroidectomy: association with hypocalcemia. Head Neck. 2015;37:393-5.

37. Sheahan P, Mehanna R, Basheeth N, Murphy MS. Is systematic identification of all four parathyroid glands necessary during total thyroidectomy? A prospective study. Laryngoscope. 2013:123:2324-8.

38. Sakorafas GH, Stafyla V, Bramis C, Kotsifopoulos N, Kolettis T, Kassaras G. Incidental parathyroidectomy during thyroid surgery: an underappreciated complication of thyroidectomy. World J Surg. 2005;29:1539-43.

39. Page C, Strunski V. Parathyroid risk in total thyroidectomy for bilateral, benign, multinodular goitre: report of 351 surgical cases. J Laryngol Otol. 2007;121:237-41.

\section{Ready to submit your research? Choose BMC and benefit from:}

- fast, convenient online submission

- thorough peer review by experienced researchers in your field

- rapid publication on acceptance

- support for research data, including large and complex data types

- gold Open Access which fosters wider collaboration and increased citations

- maximum visibility for your research: over $100 \mathrm{M}$ website views per year

At BMC, research is always in progress.

Learn more biomedcentral.com/submissions 